and Co., Ltd., has been appointed head of the new department under the general direction of $\mathrm{Mr}$. S. R. Howes, a director of United Steel, who, as general manager of Samuel Fox up to June 1956, was responsible for introducing operationel research methods at that works, where they have been applied to production control.

\section{Standards of Light}

The Light Division of the National Physical Laboratory has recently completed a new comparison of its secondary standard lamps with the internationally agreod primary standard light source. The British secondary standards are special tungsten filament vacuum lamps held by the Light Division. The international standard is a small ceramic tube, or cavity-radiator, immersed in a crucible-full of pure platinum. The metal is first melted and then slowly cooled. During the short period while solidification is teking place, the temperature remains stationary at the freezing point of platinum. At this temperature, at which the observations are made, the inside of the small radiator has, by definition, a luminance of 60 candeless per square centimetre. More than a hundred 'melts and freezes', obtained with the aid of a high-frequency induction furnace, were used for amassing sufficient observations, which were made by precise photoelectric methods. Because of the Second World War, no such comparison had been made since the occasion, some twenty years ago, when the National Physical Laboratory lamps were first calibrated in this way. Nevertheless, the values now found for their intensity agree, to within one half of one per cent, with the previous ones.

\section{The Night Sky, 1957}

A BookIst entitled "The Night Sky, 1957", containing charts of the sky for each month, has recently been issued by The Times Publishing Company, Ltd. (London, 1957 ; 3s.). Computations were made for the latitude of London, but for most practical purposes it may be used for any part of Great Britain. Very clear directions are given regarding the use of the maps, which show, in addition to the stars, the positions of the planets at 11 p.m. at the beginning of each month. Data concerning the Moon, eclipses, occultations of planets and transit of Mercury are also provided, and this compilation will prove very helpful to everyone who is interested in studying the heavens from month to month.

Emission Spectra in the Smaller Magellanic Cloud

THE results obtained on $\mathrm{ADH}$ spectrum plates of stellar-like objects in the Small Magellanic Cloud are discussed by E. M. Lindsay in a paper entitled "Emission Objects in the Small Magellanic Cloud showing the $\mathrm{N}_{1}, \mathrm{~N}_{2}$ Nebular Lines" (Mon. Not. Roy. Astro. Soc., 115, 3 ; 1955). The paper deals only with those which show the $\mathrm{N}_{1}, \mathrm{~N}_{2}$ nebular emission lines $(\lambda \lambda$ 5007, 4959) -thirty-three altogether-which were divided into two groups. Group i contrains thirteen objects associated with nebulosity and are early-type stars exciting the surrounding nebulasity. Taking a modulus of $m-M=18 \cdot 9$ for the Cloud, the mean photographic magnitude for these objects is $M=-4 \cdot 9 \pm 0 \cdot 6$, and a mean colour index (blue minus red photographic) of $-0.47 \pm 0.19$. Group ii contains seventeen objects which are not associated with nebulosity, have little or no continuous spectra, and have a mean absolute photographic magnitude of $-3 \cdot 7 \pm 0 \cdot 6$ and mean colour index $+0 \cdot 77 \pm 0 \cdot 29$. It is suggested that these objects are planetary nebulæ. Eleven other objects showing $\mathrm{H} \alpha$ emission and with the same characteristics as the members of Group ii are possible planetaries. The results of the investigation are shown in detail in the paper in seven tables, the last of which gives the distribution of planetary nebulæ with respect to absolute magnitude, and a plate shows the distribution of probable and possible planetary nebulæ in the Small Magellanic Cloud. One important matter is referred to in the paper; although the Armagh and Harvard blue photographic magnitudes are in fair agreement, the colour indices differ radically in four cases, and it is suggested that part of this may represent the difficulty of estimating magnitudes of stars involved in nebulosity. This difficulty should be appreciated by observers who estimate the magnitude of a comet with a strong central condensation, the divergences in the estimate being sometimes considerable. It was found that, when the nebulosity became sufficiently dense to be troublesome, the estimates of the magnitudes of the stars becarne systematically fainter with inereasing density.

\section{The Haughley Experiment}

IN 1939, the Local Medical and Panel Committee of the County of Cheshire, representing some six hundred general practitioners, issued a "Medical Testament" (Brit. Med. J., i, supp. p. 157; 1939) deploring the fact that knowledge of how to prevent sickness had made so little progress and affirming its belief that the basis of such prevention was essentially nutritional. Since then, medicine has made further advances in the treatment of disease, and agriculture and food technology together ensure an abundance of food at all seasons of the year, but the desired mental and physical health of the community seems further away than ever. There are many possible reasons for this, and one at least is that it is the cumulative effect of the intensified processing to which practically every article of our present-day diet is now subjected. The Soil Association believes (Brit. Dent. $J ., 102,61$; 1957 ; Lancet, $i, 144 ; 1957)$ it is necessary to look still deeper and that it is of vital importance to wean food producers away from their pre-occupation with nitrogenphosphorus-potaseium fertilizers and to teach them to think of the soil and its erops and the animals that live on those crops as one organic whole. Since 1940, the Association has been engaged on a farming experiment at Haughley, Suffolk, putting its ideas to the test (J. Soil Assoc., October 1956). It appreciates the extreme difficulty of such work but claims that results achieved so far certainly warrant its continuance. Unless public support is forthcoming, however, it seems that the experiment will have to end. Ecological research (which is what this is) must, of necessity, be long-term, and meanwhile the problem grows increasingly urgent. Here is an experimentapparently the only one of its kind in Britain-which has the first sixteen years work already accomplished; whether or not it ultimately provides the answer, it can scarcely be shrugged aside as of no importance.

\section{Tranquillizing Drugs in the United States}

TraNQUHILIING drugs include reserpine (an alkaloid from Rauwolfia serpentina) and a variety of synthetic compounds such as chlorpromazine and 